\title{
PENGEMBANGAN PERANGKAT LUNAK SISTEM INFORMASI GEOGRAFIS BERBASIS WEB
}

\author{
Budi Santosa \\ JI. Babarsari 2 Tambakbayan 55281 Telp (0274) 485323 \\ Jurusan Teknik Informatika UPN “Veteran" Yogyakarta \\ e-mail : dissan@if.upnyk.co.id
}

\begin{abstract}
Abstrak
Geospatial information is currently not only can be displayed using GIS software in a stand alone but can use the Internet as a medium for distributing geospatial information. Through the internet the whole population in the world can access geospatial information and provides a medium for geographic information processing desired without being limited by location. Web-based GIS map evolved from a web and client server architecture for distributed into a unity. Internet technology provides a new form for all functions of information systems is data collection, data storage, data retrieval (retrieving), data analysis and visualization of data. In this paper, the latest technology, web-based GIS with emphasis on architecture and stage of development of web-based GIS software that starts from the needs analysis to the maintenance stage. The implementation phase of the development of web-based GIS software to produce a web-based GIS product is right with the right process as well.
\end{abstract}

Keywords: SIG with Web Based, Technology, Development, Software

Informasi geospasial saat ini tidak hanya dapat ditampilkan menggunakan software SIG secara stand alone tetapi dapat memanfaatkan internet sebagai media penyebaran informasi geospasial. Melalui internet seluruh penduduk di dunia dapat mengakses informasi geospasial serta menyediakan media untuk pemrosesan informasi geografi yang diinginkan tanpa dibatasi oleh lokasi. SIG berbasis web berevolusi dari peta web dan arsitektur client server untuk didistribusikan menjadi sebuah kesatuan. Teknologi internet memberikan bentuk yang baru bagi seluruh fungsi dari sistem informasi yaitu pengumpulan data, penyimpanan data, pengambilan kembali data (retrieving), analisa data dan visualisasi data. Di dalam makalah ini akan dijelaskan teknologi terbaru SIG berbasis web dengan penekanan pada arsitekturnya dan tahapan pengembangan perangkat lunak SIG berbasis web yang dimulai dari analisa kebutuhan sampai pada tahapan pemeliharaan. Penerapan tahapan pengembangan perangkat lunak SIG berbasis web menghasilkan suatu produk SIG berbasis web yang benar dengan proses yang benar pula.

Kata kunci : SIG berbasis web, teknlogi, pengembangan, perangkat lunak

\section{PENDAHULUAN}

Perangkat lunak SIG memungkinkan pengguna untuk menampilkan data spasial dengan format yang sesuai. Sebagai hasilnya, interpretasi data spasial menjadi lebih mudah untuk dipahami. Namun tidak semua orang mempunyai akses ke SIG dan mau menggunakan waktunya untuk menggunakan perangkat lunak SIG secara efisien. Beberapa organisasi pemerintahan maupun non pemerintahan mempunyai kebutuhan untuk menyebarkan peta dan tool untuk pemrosesannya kepada pengguna tanpa dibatasi oleh waktu dan lokasi. SIG berbasis web menjadi cara yang mudah dan murah untuk melakukan penyebaran data geospasial dan sebagai tool untuk pemrosesan data geospasial.

Teknologi internet telah menyediakan sarana untuk terwujudnya kebutuhan tersebut. Kemampuan untuk memperoleh informasi melalui internet membuat para penyedia data spasial mengeksplorasi sumber daya internet di dalam menyebarkan informasi spasial. Agar implementasi SIG berbasis web ini berhasil maka harus memperhatikan implementasi sebagai suatu proses dan bukan hanya sebagai tahapan yang harus dilalui. Implementasi harus mempertimbangkan teknologi yang tersedia dan kebutuhan-kebutuhan dari aplikasi yang akan dikembangkan.

Di dalam makalah ini akan dijelaskan teknologi terbaru dari SIG berbasis web dengan membandingkan berbagai teknologi SIG berbasis web dan juga siklus pengembangan perangkat lunak yang diterapkan pada pengembangan SIG berbasis web 


\section{Interactive Web Maps}

Terdapat beberapa level teknologi untuk menampilkan data peta pada web, dimulai dari situs yang menampilkan peta statis sampai dengan situs yang mendukung peta dinamis, peta interaktif dengan bermacam platform komputer dan sistem operasi. Di dalam SIG berbasis web, tantangan utama adalah bagaimana menampilkan peta secara interaktif. Konsorsium Open GIS, suatu grup khusus untuk yang dibentuk untuk membahas WWW Mapping dan berbagai isu tentang SIG berbasis web. Grup ini telah mengembangkan suatu model dasar Interactive Web Maps seperti terlihat pada gambar 1.

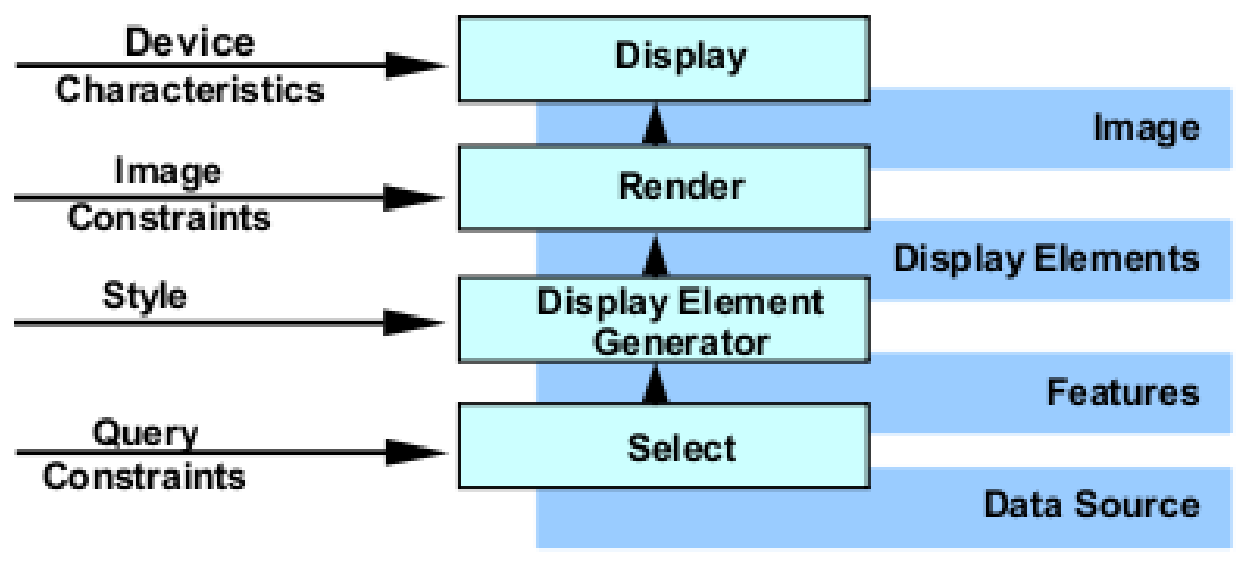

Gambar 1. Model OpenGIS (Doyle, 1999)

Model ini merupakan tool yang sangat berguna untuk menganalisa dan membandingkan perbedaan arsitektur Internet Map Servers dan aplikasi SIG berbasis web yang lain.

Model ini mempunyai 4 tingkat, yaitu :

1. Select, yaitu proses untuk memperoleh data dari sumber data geospatsial berdasar pada batasan query seperti area pencarian dan seleksi tematik

2. Display Element Generator, yaitu proses untuk merubah data geospasial kedalam urutan display elemen. Proses ini akan menyertakan simbol, bentuk line, mengisi style ke fitur spasial, men-generate anotasi dari atribut alfanumerik, mengurutkan display elemen dan melakukan pemrosesan grafis yang lain

3. Render, yaitu proses untuk mengambil elemen display dan men-generate peta yang dirender. Contoh peta render adalah, file GIF atau file postscript

4. Display, yaitu proses untuk menampilkan peta kepada user pada melalui peralatan display

Diantara 4 tingkatan tersebut, terdapat tiga tipe data yang berbeda :

a. Fitur - fitur dan coverage's (sebagai contoh data raster) yang diperoleh dari proses Seleksi

b. Display elemen yang dihasilkan dari Display Element Generator

c. Image yang dihasilkan dari Render

Kemampuan selanjutnya untuk peta web interaktif adalah mengijinkan pengguna untuk menambahkan themes baru pada peta dari katalog sumber data yang tersedia. Hal ini dapat dicapai dengan menentukan seluruh theme atau dengan melakukan queri data atribut maupun spasial yang memenuhi kriteria (Strand, 1998). Peta yang tersusun dari beberapa theme, setiap theme akan ditampilkan sebagai layer grafis pada peta. Pengguna diijinkan untuk memilih theme mana yang akan ditampilkan. 


\subsection{Internet Map Servers}

Aplikasi Internet Map Server (IMS) mengijinkan pengelola basis data SIG untuk dengan mudah membuat data spasialnya diakses melalui web browser ke pengguna.

Agar IMS dapat bekerja dibutuhkan dua komponen fungsi. Komponen pertama adalah mesin pmroses data spasial (processing engine). Mesin ini berjalan pada sisi server sebagai service yang disebut Servlet atau aplikasi Common Gateway Interface (CGI) dan melakukan pemrosesan data spasial menjadi suatu peta. Komponen kedua adalah web server yang mengatur permintaan yang datang dan menjawabnya dengan data peta yang dibutuhkan ke sisi pengguna. Produk akhirnya adalah suatu peta dengan format image JPEG atau GIF atau vektor, yang dikirimkan balik ke browser pengguna atau berupa aliran data yang diterjemahkan ke browser pengguna.

IMS yang mengirimkan kembali image, mempunyai kemampuan yang terbatas yaitu tidak dapat di perluas lagi di luar pan, zoom, dan queri dasar atribut vektor. Beberapa situs IMS menyediakan plug-in dan HTML yang sangat berguna bagi pengguna yang sering menggunakannya.

Beberapa IMS yang paling sering digunakan disajikan pada tabel 1.

Tabel 1. Beberapa Internet Map Server (AA. Alesheikh,2002)

\begin{tabular}{|c|c|c|c|c|}
\hline Internet Map Server & $\begin{array}{l}\text { Transferred } \\
\text { Geo data }\end{array}$ & $\begin{array}{l}\text { Platform of } \\
\text { IMS }\end{array}$ & $\begin{array}{l}\text { Browser } \\
\text { Extension }\end{array}$ & Data Interface \\
\hline ArcView IMS 1.0a (ESRI) & Raster & $\begin{array}{l}\text { UNIX, } \\
\text { WIN 9X, NT } \\
\end{array}$ & Html, Applet & $\begin{array}{l}\text { Shapefiles, Coverage's, } \\
\text { SDE Layer, ... }\end{array}$ \\
\hline $\begin{array}{l}\text { MapObjects IMS } 2.0 \\
\text { (ESRI) }\end{array}$ & Raster & WIN 9X, NT & Html, Applet & $\begin{array}{l}\text { Shapefiles, Coverage's, } \\
\text { SDE Layer, ... }\end{array}$ \\
\hline Arc IMS 3.1 (ESRI) & $\begin{array}{l}\text { Raster, Vector, } \\
\text { (Internal ESRI } \\
\text { formats) }\end{array}$ & WIN 98,NT & Html, Applet & $\begin{array}{l}\text { Shapefiles, Coverage's, } \\
\text { SDE Layer, ... }\end{array}$ \\
\hline $\begin{array}{l}\text { MapXtreme NT Ver } 2.0 \\
\text { (MapInfo) }\end{array}$ & Raster & WIN NT & Html, Applet & \multirow{2}{*}{$\begin{array}{l}\text { MapInfo format map, } \\
\text { Shapefiles, } \\
\text { SDE Layer, Raster format }\end{array}$} \\
\hline $\begin{array}{l}\text { MapXtreme Java Ver } 2.0 \\
\text { (MapInfo) }\end{array}$ & Raster, Vector & $\begin{array}{l}\text { WIN NT, } \\
\text { UNIX, ... }\end{array}$ & Applet & \\
\hline MapGuide 4.0 (AutoDesk) & $\begin{array}{l}\text { Raster, } \\
\text { Vector }\end{array}$ & WIN NT & $\begin{array}{l}\text { Plug-in, ActiveX, } \\
\text { Applet }\end{array}$ & $\begin{array}{l}\text { DWG, DXF, DGN, } \\
\text { Shapefiles, Coverage's, } \\
\text { MapInfo... }\end{array}$ \\
\hline $\begin{array}{l}\text { GeoMedia Web Map / } \\
\text { Enterprise 3.0 } \\
\text { (Intergraph) }\end{array}$ & $\begin{array}{l}\text { Raster, } \\
\text { Vector }\end{array}$ & WIN NT & Plug-in, ActiveX & $\begin{array}{l}\text { MGE, Shapefiles, } \\
\text { Coverage's, MapInfo, } \\
\text { Oracle, Access, ... }\end{array}$ \\
\hline $\begin{array}{l}\text { Map Server } 3.5 \\
\text { (Minnesota DNR) }\end{array}$ & Raster, Vector & $\begin{array}{l}\text { WIN 9X, NT } \\
\text { WIN } 2 \mathrm{~K}\end{array}$ & Html, Applet & $\begin{array}{l}\text { Shapefiles, } \\
\text { SDE Layer, Raster format }\end{array}$ \\
\hline
\end{tabular}

\section{Arsitektur SIG berbasis Web}

Di dalam menjalankan tugas-tugas analisis SIG, SIG berbasis web mirip dengan tipe arsitektur tiga tingkat client server. Pemrosesan data geograsfis dibagi menjadi bagian yaitu di sisi server dan di sisi client. Pada bagian Client biasanya adalah suatu web browser, sedangkan bagian server terdiri dari Web Server, aplikasi SIG berbasis web dan basis data, seperti terlihat pada gambar 2 (Helali, 2001) 


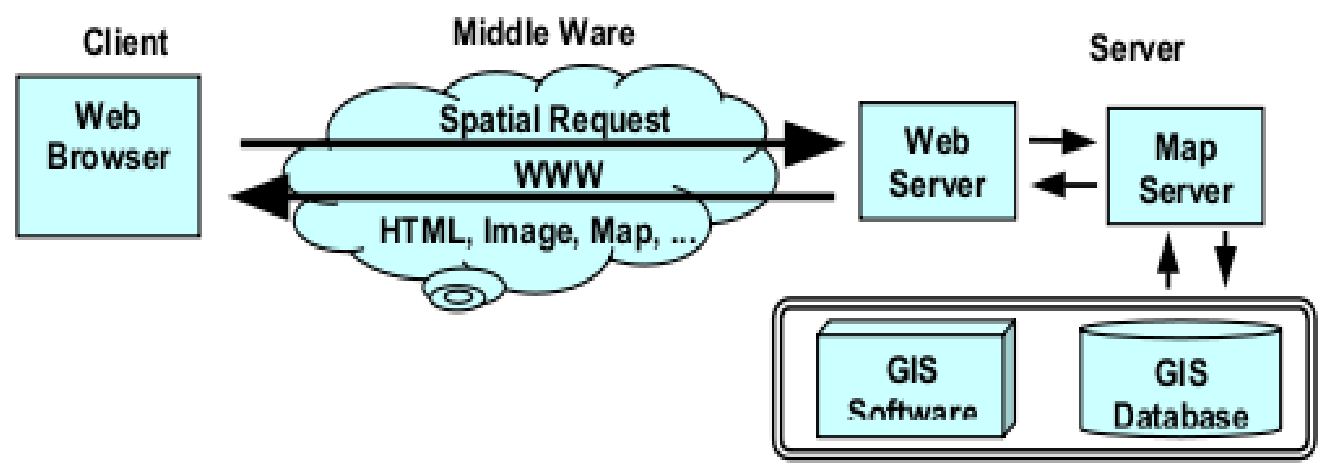

Gambar 2. Arsitektur SIG berbasis web

Model jaringan ini dikenal luas dalam organisasi, dimana beberapa komputer bertindak sebagai server dan lainnya bertindak sebagai klien. Server mempunyai hak untuk menjalankan aplikasi SIG dan menambahkan sebuah antarmuka di sisi client dan suatu middleware di sisi server untuk berkomunikasi antara klien dan aplikasi SIG.

Perkembangan terbaru dalam pemrograman berorientasi obyek memungkinkan untuk memproduksi komponen perangkat lunak, dan mengirimnya ke Client sebelum menjalankannya di mesin Client, seperti kelas Java, komponen ActiveX dan plug-in.

Model ini disebut thick client GIS . Pada arsitektur thick client, mesin akan melakukan pekerjaan pemrosesan secara lokal. Baik thin maupun thick client system memiliki beberapa keuntungan dan kelemahan, tetapi mereka bukan merupakan solusi terbaik dalam hal memanfaatkan sumber daya jaringan.

\subsection{Arsitektur Thin Client (Aplikasi di sisi Server)}

Dalam arsitektur thin client, klien hanya memiliki antarmuka pengguna untuk berkomunikasi dengan server dan menampilkan hasilnya. Semua proses dilakukan pada server seperti yang ditunjukkan pada Gambar 3.

Komputer server biasanya memiliki kemampuan yang lebih daripada client, dan mengelola sumber daya terpusat. Selain itu, ada juga kemungkinan untuk program utilitas di sisi server dapat dihubungkan ke perangkat lunak server. Gambar 3 menunjukkan skema komunikasi antara web browser, Web Server dan server SIG.

Di sisi Web Server, ada beberapa kemungkinan untuk mewujudkan koneksi SIG dengan World Wide Web; CGI, Web Server Application Programming Interface (API), Active Server Pages (ASP), Java Server Pages (JSP) dan Java-Servlet.

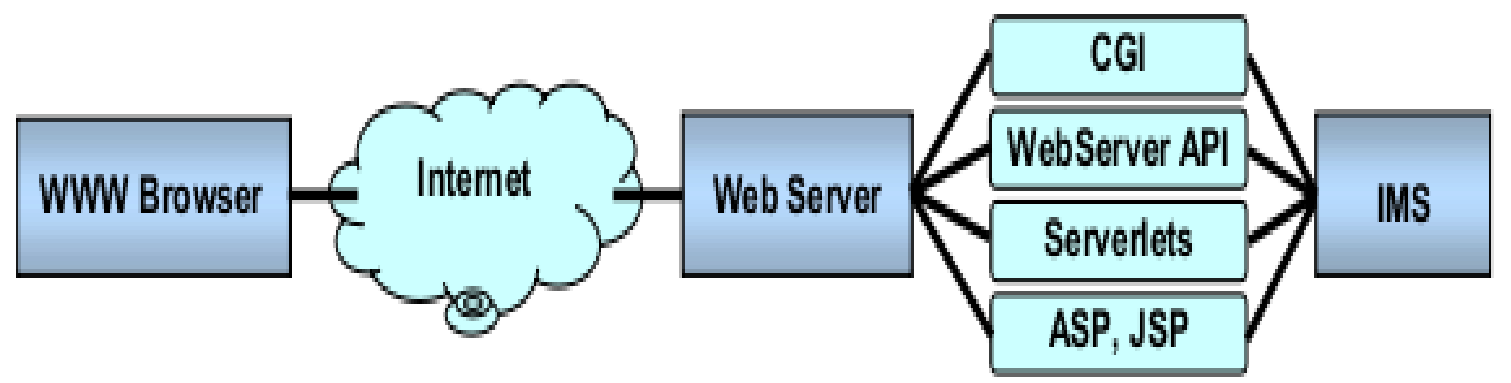

Gambar 3. Aplikasi pada sisi server

Pengguna di sisi client tidak membutuhkan pengetahuan tentang keterkaitan dari IMS di sisi server, tetapi administrator sistem atau pengembang aplikasi harus paham dengan teknik ini. Arsitektur ini digunakan dalam ArcView ESRI IMS, MapObjects IMS dan MapXtreme MapInfo. 
Kelebihan utama dari model ini adalah :
a. Kendali terpusat
b. Mudah untuk updating data
c. Selalu menamplikan versi terbaru
d. Secara umum lebih murah
e. Kemungkinan untuk Integrasi
f. Memperhatikan aspek-aspek kartografi seperti jenis huruf

Sedangkan beberapa kelemahannya adalah:

a. Tidak responsif terhadap kebutuhan lokal karena setian pengguna mempunyai kebutuhan yang berbeda-beda

b. Perlu penambahan aplikasi di sisi client untuk menjaga akuntabilitas

c. Volume database besar

d. Waktu tanggap lambat: pengguna membutuhkan waktu yang lama untuk men-download HTML

e. Kurang interaktif dikarenakan keterbatasan aplikasi dan kemampuan browser disisi client

f. Harus menambahkan plug-in agar dapat membaca file vektor

\subsection{Arsitektur Thick Client ( Aplikasi di sisi Client )}

Secara umum, web browser dapat menangani dokumen HTML, dan gambar dengan format raster. Untuk menangani format data lain seperti data vektor, klip video atau file musik, kemampuan dari browser harus diperluas. Dengan menggunakan komunikasi client-server pada arsitektur Thin Client, format file vektor tidak dapat digunakan. Untuk mengatasi masalah ini aplikasi browser memberikan suatu mekanisme yang memungkinkan program di tingkat ketiga untuk bekerja sama dengan browser sebagai Plug-in.

Fungsi antarmuka pengguna telah berkembang dari pengambilan dokumen sederhana menjadi aplikasi yang lebih interaktif. Kemajuan tersebut adalah sebagai berikut: HTML, CGI, menggunakan bentuk HTML dan CGI, Java Script untuk meningkatkan kemampuan user interface, Java applet untuk menyediakan fungsionalitas sisi klien, seperti dijelaskan pada gambar 4 (Byong-Lyol, 1998).

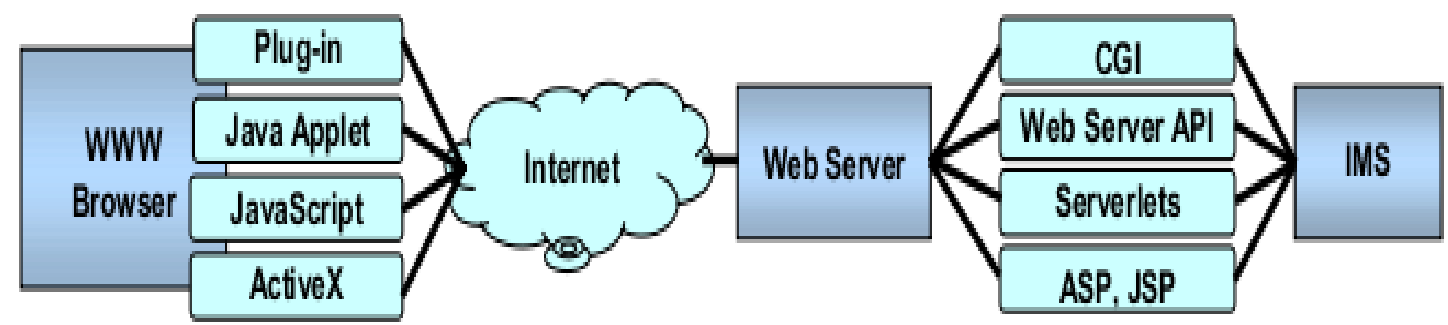

Gambar 4. Aplikasi pada sisi client

Keuntungan utama dari model ini adalah:

a. Dokumen / standar grafis tidak diperlukan

b. Vector data dapat digunakan

c. Kualitas gambar tidak terbatas pada GIF dan JPEG

d. Antarmuka modern dimungkinkan untuk diterapkan.

Sedangkan beberapa kerugiannya adalah sebagai berikut :

a. Pengguna memerlukan beberapa software tambahan

b. Platform/browser tidak kompatibel 


\subsection{Arsitektur Medium Client}

Untuk menghindari data vektor di sisi client dan untuk mengurangi beberapa permasalahan di arsitektur sebelumnya, ditawarkan arsitektur Medium Client. Dengan menggunakan extensions di kedua sisi client dan server, client akan mempunyai lebih banyak fungsionalitas dibandingkan dengan arsitektur thin client. Pada gambar 5 dijelaskan bahwa empat komponen dalam peta interaktif digambarkan sebagai suatu layanan, dengan masingmasing antarmuka yang bisa diakses oleh client.

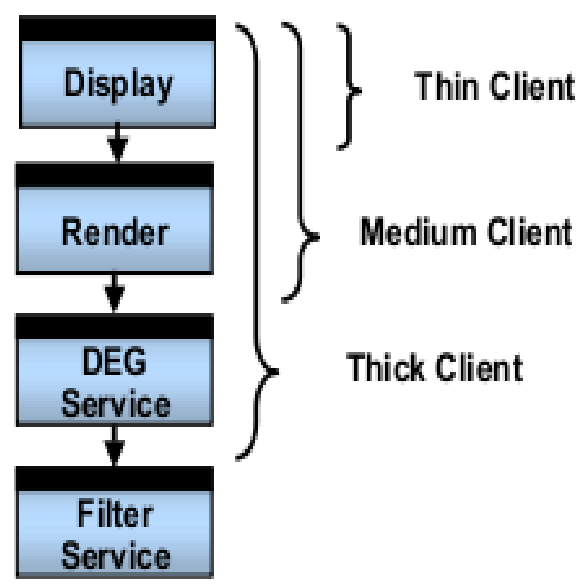

\section{Gambar 5. Posisi medium client menurut OpenGIS}

Dengan kata lain, jika komputer pengguna hanya berisi layanan display, maka pengguna dikatakan menggunakan thin client. Jika komputer pengguna dilengkapi dengan layanan render, maka pengguna dikatakan menggunakan medium client.

Pada akhirnya jika komputer pengguna juga berisi layanan display element generator, maka dikatakan bahwa pengguna menggunakan thick client.

\subsection{Arsitektur Terdistribusi}

Perkembangan terkini dalam teknologi informasi telah menghasilkan sejumlah objek arsitektur terdistribusi yang menyediakan framework yang diperlukan untuk membangun aplikasi terdistribusi. Kerangka kerja ini juga mendukung sejumlah besar server dan aplikasi berjalan secara bersamaan. Banyak framework menyediakan mekanisme untuk interoperabilitas (Kafatos, 1999).

Sebagai contoh, arsitektur Distributed Component Object Model di Windows dan Java Remote Method Invocation (RMI) di Java Virtual Machine (JVM) adalah protokol paling populer yang digunakan dalam beberapa kasus yang berbeda. Arsitektur-arsitektur ini dapat diterapkan untuk SIG untuk memperbaiki tradisional klien / server model GIS dan mengembangkan model SIG terdistribusi.

Ide dasar dari model SIG terdistribusi ini adalah bahwa sebuah program klien, baik di browser Internet atau aplikasi independen, harus dapat mengakses sumber daya yang didistribusikan di seluruh jaringan. Sumber daya di sini merujuk kepada kedua komponen geodata dan geoprocessing yang tersedia dalam jaringan. Dalam konteks ini klien dan server tidak mengacu pada mesin tertentu. Setiap mesin, ketika melakukan permintaan sumber daya selama proses tersebut, disebut sebagai klien, dan mesin yang menyediakan sumber daya disebut sebagai server. Dalam program khusus, jika diperlukan klien dapat terhubung ke beberapa server, dan sebuah mesin yang spesifik dapat bertindak sebagai klien pada suatu waktu dan sebagai server di saat yang lain.

Suatu model SIG terdistribusi yang ideal layanan harus menjadi geodata dimana saja dan geoprocessing di mana saja, yang berarti geodata dan tools untuk geoprocessing dapat didistribusikan secara fleksibel di mana saja dalam jaringan. 
Komponen geodata dan geoprocessing tidak harus berada di situs yang sama, tetapi mereka harus dapat bekerja sama atau mengintegrasikan setiap kali mereka dibutuhkan untuk menyelesaikan suatu tugas yang spesifik (Yuan, 2000).

\section{Siklus Pengembangan Perangkat Lunak SIG berbasis Web}

Mengembangkan sebuah SIG berbasi web berbeda dengan sekedar membeli perangkat keras dan perangkat lunak yang sesuai. Beberapa strategi telah diusulkan untuk memberikan keberhasilan dalam implementasinya (Alesheikh \& Helali 2001).

Strategi implementasi SIG ini telah diuji secara ilmiah dan telah dimodifikasi sehingga kebutuhan suatu pelaksanaan proyek pengembagan SIG berbasis dapat dipenuhi dengan biaya dan waktu yang minimum.

Pada gambar 6 ditunjukkan siklus pengembangan SIG berbasis web yang digambarkan dalam 8 kegiatan utama, dimulai dengan analisis kebutuhan dan berakhir dengan penggunaan dan pemeliharaan sistem SIG berbasis web (Alesheikh, Helali \& Behroz, 2002).

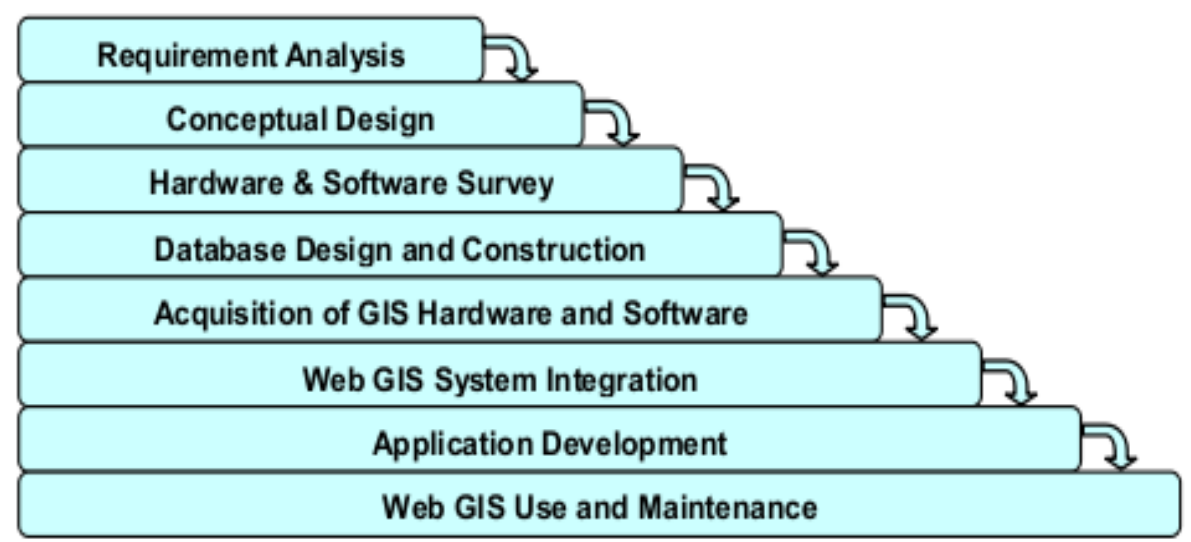

Gambar 6. Siklus Pengembangan SIG Berbasis WEB

Penjelasan dari tahapan-tahapan pengembangan SIG berbasis web adalah sebagai berikut :

\section{Analisa Kebutuhan (Requirement Analysis)}

Di dalam tahapan ini harus ditentukan terlebih dahulu tujuan yang ingin dicapai dari sistem yang akan dibuat. Langkah analisis kebutuhan dapat dilakukan melalui wawancara dengan calon pengguna. Langkah ini menghasilkan dua bagian penting dari informasi :

a. Fungsi-fungsi fungsi yang diperlukan.

Fungsi-fungsi yang diperlukan adalah fungsi visualisasi dasar seperti Pan, Zoom, dan fungsi lain yang lebih maju seperti identifikasi objek, query spasial, dan jalan terpendek.

b. Data geografis yang diperlukan.

Informasi yang diperoleh dalam kegiatan analisis kebutuhan akan dilanjutkan ketahap berikutnya yaitu disain konseptual SIG

\section{Disain konseptual (Conceptual Design)}

Setelah data yang dibutuhkan telah diidentifikasi, dirancanglah model data yang diwujudkan dalam diagram relasi entitas ( Entity Relationship Diagram ).

3. Survey terhadap Ketersediaan Perangkat Keras dan Perangkat Lunak ( Hardware and Software Survey ) 
Pemilihan perangkat lunak yang cocok merupakan langkah penting dalam kesuksesan tahapan implementasi. Perangkat Lunak dievaluasi pada fungsionalitas dan kinerja, dan independen dari hardware dan sistem operasi.

\section{Perancangan Basisdata dan Konstruksi ( Database Design and Construction )}

Tujuan utama pada tahapan ini adalah untuk menentukan "bagaimana" Web GIS merancang kebutuhan aplikasi yang diperlukan. Perancangan basisdata meliputi bagaiman mendefinisikan bagaimana grafis akan dilambangkan (yaitu, warna, berat, ukuran, simbol, dII), bagaimana bentuk struktur file grafis, bagaimana bentuk struktur atribut file non grafis, layer mana yang aktif, dalam skala apa layer yang harus ditampilkan, bagaimana produk SIG akan ditampilkan (misalnya, peta tata letak lembar, format laporan, dII), dan manajemen dan pembatasan keamanan apa yang akan dikenakan pada akses file.

Kegiatan yang dilakukan adalah sebagai berikut :

a. Memilih sumber (dokumen, peta, file digital, dll) untuk setiap entitas dan atribut yangtermasuk dalam diagram Entitas-Relationship

b. Melakukan pengaturan rancangan basisdata (baik secara logik maupun fisik)

c. Menentukan prosedur untuk mengkonversi data dari media sumber ke basisdata.

d. Menetapkan prosedur untuk mengelola dan memelihara basisdata.

\section{Akuisisi Perangkat Keras dan Perangkat Lunak SIG (Acquisition Of GIS Hardware And Software)}

Kegiatan perancangan basisdata dilakukan bersamaan dengan aktifitas pemilihan perangkat keras dan perangkat lunak SIG. Perancangan prosedur dan basisdata tidak dapat diselesaikan sebelum hardware dan software SIG telah dipilih sementara pada saat yang sama pemilihan hardware dan software SIG tidak dapat diselesaikan sampai SIG yang dipilih dapat menunjukkan fungsi-fungsi yang diperlukan pada data.

Berdasarkan kemampuan fungsional, dukungan vendor, biaya / fee pemeliharaan, dan survei dari perangkat keras yang tersedia / perangkat lunak, yang telah dibeli, dan semua yang diperlukan renovasi ruang, kabel, dan penataan kembali lingkungan hidup telah dilakukan.

\section{Integrasi Sistem SIG berbasis Web (WebGIS System Integration )}

Pada tahap ini proses pengembangan SIG berbasis web, hardware dan software telah diakuisisi dan konversi data telah selesai. Tujuan dari tahap ini kemudian untuk mengintegrasikan komponen yang berbeda dari hardware dan software, untuk menguji dan untuk memastikan seluruh komponen bekerja seperti yang diharapkan, dan untuk memulai semua prosedur yang diperlukan untuk menggunakan SIG.

\section{Pengembangan Aplikasi (Application Development)}

Pada tahapan ini seluruh kebutuhan dari software yang telah ditentukan dalam tahapan analisa maupun perancangan diwujudkan dalam bentuk aplikasi. Kemudahan untuk digunakan, user friendly, dan volume data transfer menjadi hal yang sangat diperhatikan pada tahap ini.

Gambar 7 memperlihatkan antarmuka awal dari aplikasi yang telah dikembangkan (Santosa,2009). 


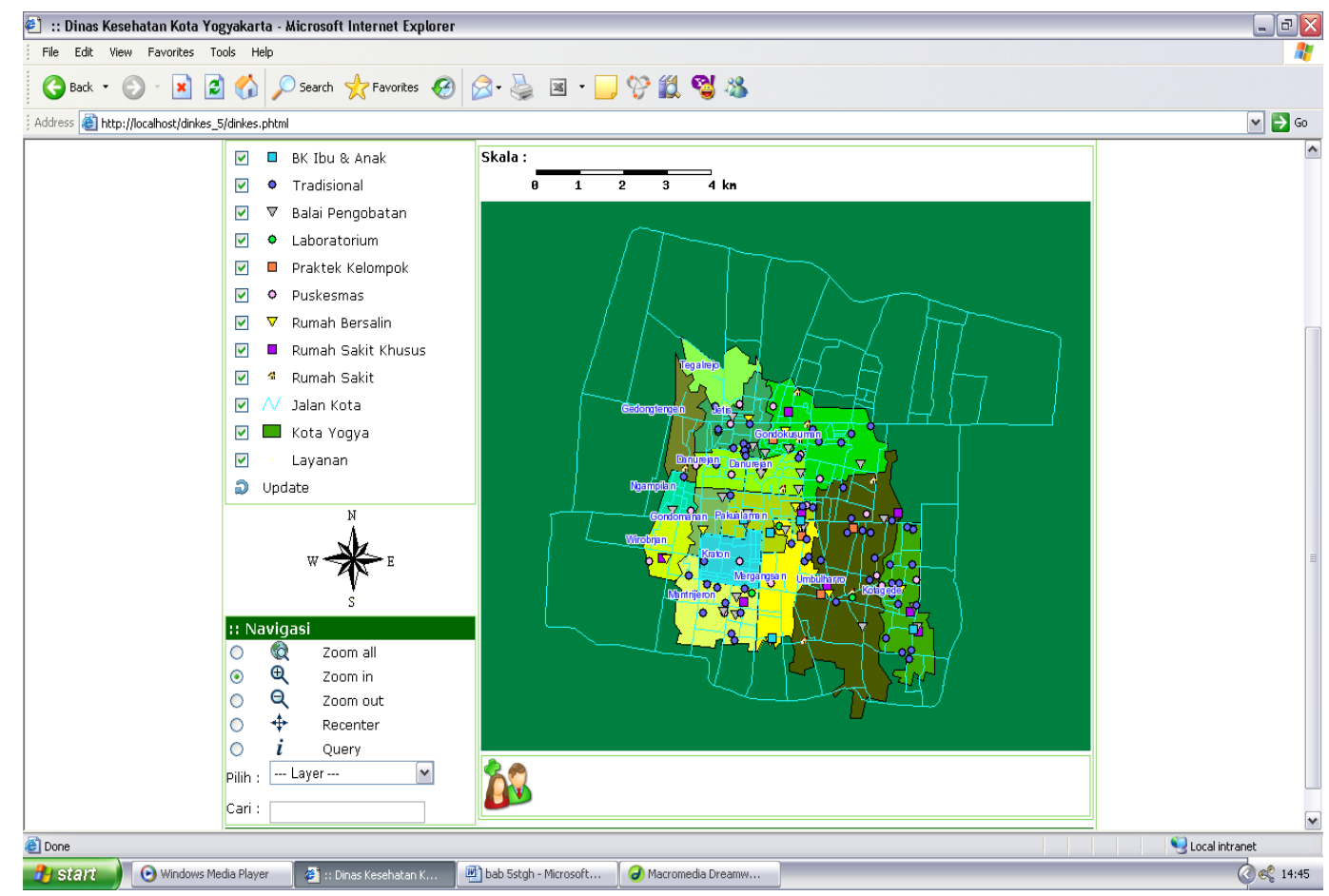

Gambar 7. Antarmuka aplikasi SIG berbasis Web yang telah dikembangkan

\section{Penggunaan dan Pemeliharaan SIG berbasis Web (Web GIS Use And Maintenance )}

Langkah terakhir dalam implementasi SIG berbasis web adalah untuk menempatkan sistem untuk digunakan. Dengan selesainya sistem integrasi dan pengujian, serta seluruh siap untuk digunakan, maka sistem ini diberikan kepada pengguna.

Kegiatan yang dilakukan adalah sebagai berikut :

a. Dukungan dan layanan terhadap pengguna di mana aplikasi yang baru akan diterapkan

b. Sistem pemeliharaan (basisdata, hardware, software) agar SIG berbasis web berjalan lancar

\section{PENUTUP}

Proses pengembangan SIG berbasis web menghadapi tantangan baru seperti inovasi teknologi, besar dan kecepatan transfer data dan kebutuhan pengguna umum.

Hasil pengamatan yang telah dilakukan adalah sebagai berikut :

a. Pengembangan SIG berbasis web tidak hanya sekedar membeli perangkat lunak dan perangkat keras SIG. Agar pengembangan SIG berbasis web ini berhasil, tahapan implementasi harus diperhatikan sebagai sebuah pada proses daripada sekedar suatu tahapan. Proses ini dimulai dengan analisis kebutuhan yang diakhiri dengan pemeliharaan dan penggunaan SIG berbasis web.

b. Tahapan Analisa Kebutuhan akan menentukan fungsi fungsi yang dibutuhkan oleh perangkat lunak yang dikembangkan, sehingga berpengaruh pada penentuan arsitektur SIG berbasis web yang akan digunakan. 


\section{DAFTAR PUSTAKA}

Alesheikh, Helali \& Behroz (2002), Web GIS: Technologies and Its Applications, Symposium on Geospatial Theory, Processing and Applications, Ottawa 2002

Alesheikh AA \& Helali H (2001), Distributing National Geospatial Information. Proceedings of Digital Earth 2001, Fredericton, NB, Canada

Byong-Lyol L, Young-Chan K, Jin-I Y (1998) Web interface for GIS in Agriculture. By The Asian Federation for Information Technology in Agriculture

Doyle A (1999), Web Map Server Interface Specification. OpenGIS Project Document 99-077r1 URL: http://www.opengis.org

Helali H (2001) Design and Implementation of a Web GIS for the City of Tehran. MSc thesis, Department Of Geodesy And Geomatics Engineering K.N.Toosi University Of Technology, Tehran, Iran

Kafatos E, et al (1999) Earth Observing Data Systems in the Internet Era. Photogrammetric Engineering \& Remote Sensing, May 1999, Vol. 65, No. 5, pp540-548

Santosa, Budi (2009), Web based Application for Mapping of Public Health Services and Facilities, International Industrial Informatics Seminar 2009, UIN Sunan Kalijaga, Yogyakarta

Strand EJ (1998) What's the Right Way to Web Map Data. Synergetics Inc. URL: http://www.geoplace.com/gw/1998/1298/1298nab.asp

Yuan S (2000) Development of A Distributed Geoprocessing Service Model, MSc thesis, Department Geomatics Engineering, Calgary, Alberta, Canada 